\title{
Age-related declines in muscle and respiratory function are proportionate to declines in performance in Master Track Cyclists
}

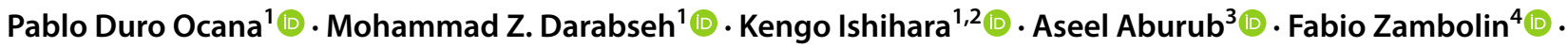

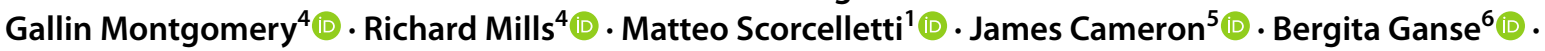 \\ Hans Degens ${ }^{1,7}$ (1) $\cdot$ Liam Bagley ${ }^{1}$ (i)
}

Received: 24 February 2021 / Accepted: 25 August 2021 / Published online: 13 September 2021

(c) The Author(s) 2021

\begin{abstract}
Purpose Respiratory and musculoskeletal function decline with age, irrespective of physical activity levels. Previous work has suggested that the age-related rate of decline in function of these two systems might be similar, but it is not known to what extent each system contributes to decreasing performance in ageing master cyclists. Therefore, the purposes of this study are (1) whether the age-related rate of decline in respiratory function, respiratory muscle strength, muscle architecture, muscle function, haemoglobin concentration, haematocrit and performance in master cyclists is uniform and (2) which parameters contribute most to the reduction in performance with age.

Methods Master cyclists were recruited during the Track Cycling Masters World Championship 2019 in Manchester. Respiratory function and respiratory muscle strength were determined using spirometry and a mouth pressure device, respectively. Muscle architecture was determined using ultrasonography, and muscle function by countermovement jump.

Results Forced expiratory volume in the first second, forced vital capacity, fascicle length, muscle thickness, take-off velocity, jump power, jump power per body mass, handgrip strength, haemoglobin concentration and performance correlated negatively with age $(p \leq 0.043)$. The age-related rate of decline did not differ significantly between parameters $(p=0.124)$, but it was slower for haemoglobin concentration $(p=0.041)$. Take-off velocity was the major determinant of performance in 200,500 and $2000 \mathrm{~m}$ track cycling disciplines $\left(R_{\text {adj }}^{2}=0.675,0.786\right.$ and 0.769 , respectively; $\left.p<0.001\right)$.
\end{abstract}

Conclusion Age-related decline in respiratory and muscle system is accompanied by a similar rate of decline in performance. The major contribution to the age-related decline of performance is reduced muscle function, specifically take-off velocity.

Keywords Master athletes $\cdot$ Lung function $\cdot$ Respiratory function $\cdot$ Maximum respiratory pressure $\cdot$ Muscle function . Muscle architecture $\cdot$ Ageing $\cdot$ Track cycling

\section{Abbreviations}

CV Coefficient of variance

FVC Force vital capacity

$\mathrm{FVC}_{\text {pred }} \quad$ Force vital capacity predictive values

$\mathrm{FEV}_{1} \quad$ Force expiratory volume during the first second

Communicated by Susan Hopkins.

Pablo Duro Ocana and Mohammad Z. Darabseh contributed equally to this manuscript and they should be considered joint first author.

Pablo Duro Ocana

P.Duro.Ocana@mmu.ac.uk

Extended author information available on the last page of the article

$\begin{array}{ll}\text { FEV }_{1 \text { pred }} & \begin{array}{l}\text { Force expiratory volume during the first sec- } \\ \text { ond predictive values } \\ \text { g }\end{array} \\ \mathrm{Hb} & \text { Havity } \\ \mathrm{Hct} & \text { Haemoglobin } \\ \mathrm{L}_{\mathrm{f}} & \text { Fascicle length } \\ \mathrm{MEP} & \text { Maximal expiratory pressure } \\ \mathrm{MIP} & \text { Maximal inspiratory pressure } \\ \mathrm{MT} & \text { Muscle thickness } \\ \mathrm{PEF} & \text { Peak expiratory flow } \\ \mathrm{PEF} & \text { Peak expiratory flow predictive values } \\ \mathrm{SNIP} & \text { Nasal inspiratory pressure } \\ \mathrm{T}_{\text {air }} & \text { Time on air } \\ \mathrm{VL} & \text { Vastus lateralis } \\ \mathrm{V}_{\text {off }} & \text { Take-off velocity }\end{array}$




\section{Introduction}

Regular physical activity is widely considered the best intervention to protect against the age-related decrement in overall fitness (McPhee et al. 2016). Indeed, the major factor of overall fitness reduction is the decline of physical activity with age (Leyk et al. 2010). Disuse and low levels of physical activity have been shown to lead to muscle atrophy (Degens and Alway 2006) and reduced ventilatory function (George et al. 2014). Even though physical activity helps to maintain high levels of fitness through age, ageing is a progressive process that affects muscle and respiratory fitness (McKendry et al. 2018). This is also reflected by the progressive decline in both pulmonary function, aerobic capacity and maximal peak power generation during the lifespan (Roman et al. 2016; Pearson et al. 2002).

The decrease in power-generating capacity is accompanied by a reduction in muscle size in both, athletes (Couppé et al. 2014) and non-athletes (McPhee et al. 2018; Couppé et al. 2014). Likewise, the respiratory muscle strength, vital capacity and other parameters of maximal ventilation show similar age-related rate of decline in athletes and non-athletes (Degens et al. 2013; HarikKhan et al. 1998; McClaran et al. 1985). It is therefore, not surprising that there is a close correlation between respiratory function and skeletal muscle index (Sawaya et al. 2018), and between maximal inspiratory pressure (MIP), maximal expiratory pressure (MEP) and handgrip strength (Efstathiou et al. 2016). In a previous cross-sectional study, we saw that anaerobic and aerobic power showed a proportional age-related rate of decline, as reflected by a constant aerobic:anaerobic power ratio throughout life (Bagley et al. 2019).

Concomitant with these changes in muscle and respiratory function is the progressive reduction in track cycling performance (world records) from middle-aged to advanced age (Union Cycliste Internationale 2021). While this provides circumstantial evidence that the age-related rate of decline in respiratory and skeletal muscle function leads to a proportional reduction in cycling performance, no studies have systematically investigated this. Taken together, it appears that related declines in physical function and performance may be due to a stochastic accumulation of (micro) damage over time (Degens 2012) that affects different systems of the human body similarly. Despite some evidence pointing toward a similar age-related decline in muscle and respiratory function, evidence is limited from studies that have analysed the decline of both systems in the same population.

Even though the physiological systems are interrelated, the age-related decline of some parameters may play a more important role than others in the reduction of specific sport performances with age. For instance, the main determinant of performance in endurance disciplines is $\mathrm{VO}_{2} \max$ (Tanaka and Seals 2003), while muscle function is the main determinant in power disciplines (Pearson et al. 2002). Cycling performance depends primarily on a combination of power output, and cardiovascular and pulmonary capacities (Phillips and Hopkins 2020), but the importance of each factor is also likely to differ between distances cycled. For example, in cycling sprint performance, the shortening velocity of the muscle is likely to be an important factor of performance, with an increasingly important contribution of aerobic power with increasing cycling distances (Martin et al. 2007). The velocity of contraction is not only determined by the contractile properties of the muscle, but also the force-generating capacity, or size of the muscle (Degens 2019). Indeed, the size of the Vastus Laterallis (VL) and Vastus Medialis muscles have been reported to be major determinants of $6 \mathrm{~s}$ cycling sprint performance (Martin et al. 2007). Further supporting this notion is the observation that the combination of lean thigh volume and pedalling rate accounted for $83 \%$ of the variability in power production ability across life in cycling sprint performance, where thigh muscle volume accounted for $76 \%$ of that variability (Martin et al. 2000). This impact of muscle mass on muscle functionality, and ultimately in performance, are also observed in recreationally active adults where the principal determinant of walking speed was found to be take-off velocity $\left(V_{\text {off }}\right)$ in a counter-movement jump (Maden-Wilkinson et al. 2015).

While expiratory flow limitations and diaphragm fatigue can be detrimental to exercise performance in endurance athletes (Dempsey et al. 2008), it is unlikely to have a significant impact on the sprint performance of track cyclists. This can, however, not be entirely excluded, as an inverse relationship between spirometry parameters and sprint performance has been reported (Bhatt et al. 2015).

Given the previously observed age-related decrements in respiratory and musculoskeletal function, and performance and the suggestion that ageing is a reflection of a stochastic accumulation of micro damage, it is hypothesized that cycling performance, skeletal muscle and respiratory function show a proportional age-related rate of decline. Due to the short duration of track cycling races, it is hypothesised that muscle architecture and function are the major determinants of track cycling performance. 


\section{Materials and methods}

\section{Study design}

Master cyclists (60 men; (38-84 years) and 15 women; (34-80 years)) were recruited during the UCI Track Cycling World Masters Championships 2019 (Manchester, United Kingdom). Participants with chronic respiratory complaints, cardiovascular, neuromuscular, or metabolic disease, or those who had a leg fracture in the past two years were excluded from the study. The study was approved by the Science and Engineering Research Ethics Committee at Manchester Metropolitan University. All participants provided written informed consent before participating, conforming to the Declaration of Helsinki.

\section{Participant characteristics}

Height (in $\mathrm{m}$ ) and body mass (in $\mathrm{kg}$ ) were assessed using a stadiometer and digital scales, respectively. The haemoglobin $(\mathrm{Hb})$ concentration (Hemocue, Ängelholm, Sweden) and haematocrit (Hct) were measured from capillary blood obtained by finger prick. Training hours per week were self-reported by participants. Age-graded performance was calculated as the performance in the best event (prime event) of a person of a given age as a percentage of the world record at that age. Participant characteristics are summarized in Table 1.

\section{Muscle architecture}

Muscle architecture was analysed using Real-time B-mode ultrasonography with a linear-array probe (VF13-5, Siemens ACUSON P500, Erlangen, Germany). Muscle thickness (MT, in mm), fascicle length $\left(L_{\mathrm{f}}\right.$, in $\left.\mathrm{mm}\right)$ and pennation angle (in degrees) of the VL muscle were determined at 50\% of the femur length (McPhee et al. 2018), while the cyclist was seated with the knee and hip at $90^{\circ}$ of flexion. All ultrasound scanning and image analysis (Image J, v1.8.0_112; National Institutes of Health, Bethesda, MA) was completed by the same investigator. All architectural parameters were given as the average of three measurements in the image. MT was defined as the shortest distance between the superficial and deep aponeuroses. $L_{\mathrm{f}}$ was calculated using the extrapolation method (Brennan et al. 2017) when necessary. The pennation angle was defined as the angle between the deep aponeurosis and the fascicles. The intra-rater coefficient of variance $(\mathrm{CV})$ for all the measurements was below $10 \%\left(\mathrm{CV} \mathrm{MT}=1 \%, \mathrm{CV} L_{\mathrm{f}}=6 \%, \mathrm{CV}\right.$ pennation angle $\left.=9 \%\right)$.

\section{Muscle function: jump power and handgrip strength}

Handgrip strength and jump power were collected as measurements of muscle function. Participants performed three countermovement jumps (CMJ) (Bagley et al. 2019) with the hands placed on the hip, on a force platform (Leonardo Mechanograph $^{\circledR}$ : Novotec Medical GmbH, Pforzheim, Germany). The jump with the highest power output (in $\mathrm{kW}$ ), was selected for final analysis. Jump power and jump power per $\mathrm{kg}$ of body mass was computed by the system (Leonardo
Table 1 Participant characteristics

\begin{tabular}{lllr}
\hline & Men & Women & $p$ value \\
\hline Age $($ years $)$ & $61 \pm 11(60)$ & $50 \pm 12(15)$ & $0.002^{*}$ \\
Height $(\mathrm{m})$ & $1.75 \pm 0.07(55)$ & $1.68 \pm 0.05(15)$ & $<0.001^{*}$ \\
Body mass $(\mathrm{kg})$ & $81.5 \pm 13.8(55)$ & $65.9 \pm 7.7(15)$ & $<0.001^{*}$ \\
BMI $\left(\mathrm{kg} / \mathrm{m}^{2}\right)$ & $26.6 \pm 3.6(55)$ & $23.2 \pm 2.4(15)$ & $0.004^{*}$ \\
{$[\mathrm{Hb}](\mathrm{g} / \mathrm{L})$} & $141 \pm 17(51)$ & $135 \pm 8(15)$ & 0.327 \\
Hct $(\%)$ & $44.9 \pm 4.1(50)$ & $42.5 \pm 3.4(14)$ & $0.035^{*}$ \\
Hb/Hct & $3.15 \pm 0.37(50)$ & $3.20 \pm 0.34(14)$ & 0.755 \\
Hours of training per week & $11.2 \pm 4.8(47)$ & $9.7 \pm 3.0(14)$ & 0.281 \\
Age-graded performance $(\%)$ & $90.7[86.5-94.5](55)$ & $92.26[88.7-95.8](13)$ & 0.274 \\
$200 \mathrm{~m}$ time (s) & $13.0[12.4-13.5](30)$ & $13.0[12.7-14.6](5)$ & 0.552 \\
500 m time (s) & $40.6[38.8-42.7](32)$ & $42.3[40.3-45.3](8)$ & 0.153 \\
2000 m time (s) & $158[150-168](25)$ & $160[156-174](10)$ & 0.321 \\
\hline
\end{tabular}

All data are presented as mean $\pm \mathrm{SD}(N)$ or median $[\mathrm{IQR}](N)$

Age-graded performance represents the median values of the prime event time of each participant normalised to the world record of the prime event at the, respective, category-age. 200, 500 and $2000 \mathrm{~m}$ time represent the median race times of all participants that competed on the respective discipline, independently of their prime event

$B M I$ Body mass index; Hb Haemoglobin; Hct Haematocrit

${ }^{*} p$ value $<0.05$ denotes significant sex effect 
Mechanography v4.4 Software ${ }^{\circledR}$ : Novotec Medical GmbH, Pforzheim, Germany). $V_{\text {off }}$ (in $\mathrm{m} \cdot \mathrm{s}^{-1}$ ) was calculated as:

$V_{\text {off }}=g \times\left(\frac{t_{\text {air }}}{2}\right)$

where $g$ is gravitational acceleration $\left(9.81 \mathrm{~m} \cdot \mathrm{s}^{-2}\right)$, and $t_{\text {air }}$ represents the flight time (s) (Degens et al. 2019).

Handgrip strength (in $\mathrm{kg}$ ) was measured with a handheld dynamometer (Takei Handgrip, Hab International Ltd. Warwickshire, United Kingdom) as an indicator of overall muscle strength (Stark et al. 2011). The elbow was placed at the side of the body and flexed at $90^{\circ}$, with the wrist in neutral position.

\section{Respiratory function (spirometry)}

Respiratory function was measured by spirometry. All spirometry measurements were performed using a Micro Medical Spiro USB Spirometer and analysed with Spida 5 software (Cardinal Health, UK). The spirometer was calibrated daily according to the ATS/ERS recommendations (Miller et al. 2005). The participants were seated with feet rested flat on the floor during the test. The participants were instructed to inhale forcefully and maximally followed by forceful exhalation while wearing a nose clip. Three successful procedures were required to conclude the test, with a maximum of 8 manoeuvres conducted to achieve 3 successful procedures. According to the ATS/ERS recommendation, a procedure was considered successful if there was a plateau in the exhalation, exhalation lasted $>6 \mathrm{~s}$, there were no coughs and between-test variations for Forced Vital Capacity $(\mathrm{FVC}$,) and Forced Expiratory Volume in the first second $\left(\mathrm{FEV}_{1}\right)$ were $<0.15 \mathrm{~L}$. The measured parameters were: $\mathrm{FEV}_{1}, \mathrm{FVC}, \mathrm{FEV}_{1} / \mathrm{FVC}$ ratio and Peak Expiratory Flow (PEF). $\mathrm{FVC}$ and $\mathrm{FEV}_{1}$ are reported in $\mathrm{L}$ and $\mathrm{PEF}$ in $\mathrm{L} / \mathrm{min}$. The predicted values for $\mathrm{FEV}_{1}\left(\mathrm{FEV}_{1 \text { pred }}\right), \mathrm{FVC}\left(\mathrm{FVC}_{\text {pred }}\right)$ and PEF $\left(\mathrm{PEF}_{\text {pred }}\right)$ were calculated as previously described (Degens et al. 2013) according to equations that include age and height as provided by The Third National Health and Nutrition Examination Survey taking into account ethnic background (Hankinson et al. 1999). Spirometer flow diagrams were examined for participants to ensure that participants were performing proper manoeuvres. The lower limit of normal (LLN) for $\mathrm{FEV}_{1} / \mathrm{FVC}$ and $\mathrm{FEV}_{1}$ were also calculated using the equations presented in Hankinson et al. (1999). Any participants with an $\mathrm{FEV}_{1} / \mathrm{FVC}$ and $\mathrm{FEV}_{1}<\mathrm{LLN}$ were excluded from the analysis.

\section{Respiratory pressure}

The maximal inspiratory (MIP) and expiratory (MEP) pressures were measured using a portable mouth pressure device (MicroRPM, Cardinal Healthcare, UK) as estimators of respiratory muscle strength. Participants were instructed to inhale or exhale as forcefully as possible after total exhalation or inhalation, respectively, into the portable MicroRPM (Hautmann et al. 2000; The American Thoracic Society 2002). To measure the maximal sniff nasal inspiratory pressure (SNIP), participants were instructed to place a probe in one of their nostrils while the other nostril was closed and then inspired as fast and as forceful as possible via the nose. For all manoeuvres, attempts were repeated, with a 30-s interval between each attempt to prevent the development of respiratory muscle fatigue, until the maximum value was achieved. Data are reported in centimetre of water $\left(\mathrm{cm} \mathrm{H}_{2} \mathrm{O}\right)$.

\section{Age-related rate of decline in muscle, respiratory function and cycling performance}

The age-related rate of decline in muscle architecture, handgrip strength, jump power, respiratory function, maximum respiratory pressures and performance was calculated as the annual percentage change from the predicted value at the age of 35 years. The predicted value at the age of 35 years was calculated for each sex separately, from the regression equation of each parameter against age.

\section{Discipline performance}

Times of individual 200, 500 and $2000 \mathrm{~m}$ disciplines for each participant were collected from the results book of the 2019 Master Track Cycling World Championships (Union Cycliste Internationale 2021). Performance was considered as the time of a participant in a given discipline as a percentage of the predicted time for a master cyclist of 35 years old. The predicted time was estimated from the linear regression between the times of all participants in a discipline and the age of the participants for each sex separately. Some participants competed in more than one event, and in that case the event with the best performance was considered their prime event and selected for analysis. The performances in 750 and $3000 \mathrm{~m}$ were not included in the analyses as only 35 - to 49-year-old people competed in these events.

\section{Statistical analysis}

Statistical analyses were performed using SPSS software (IBM Corporation, NY, US). Data were assessed for normality with the Shapiro-Wilk test. To assess differences between sexes, a multivariate ANOVA was performed with sex as factor. If the data were not normally distributed, a non-parametric test (Mann-Whitney test) was performed. An ANCOVA with sex and the different parameters as factors, and age as covariate was used to assess differences in the age-related rate of decline of the different parameters. Multiple regression analysis between the times of the 
different disciplines as independent variable, and age, sex, body mass, muscle architecture, jump power, respiratory function and respiratory pressures as dependent variables, was performed to assess the determinants of performance in each discipline. Further multiple regression analysis with the major determinant of performance was carried out to better understand what determines performance.

\section{Results}

Upon calculating the participants $\mathrm{LLN}$ for $\mathrm{FEV}_{1} / \mathrm{FVC}$, eleven participants had $<\mathrm{LLN}$ of $\mathrm{FEV}_{1} / \mathrm{FVC}$. One man participant was excluded after checking the spirometer flow diagrams. For the FEV $\mathrm{LLN}_{1}$, the remaining 10 participants had $\mathrm{FEV}_{1}>\mathrm{LLN}$ and therefore, no further participants were excluded from the analysis.

\section{Comparison between sexes}

Table 1 shows participant characteristics. The average age of the men was higher than that of the women $(p=0.002)$. Men were taller than women $(p<0.001)$ and their body mass and BMI were higher than that of women $(p \leq 0.004)$. Hct was $5.0 \%$ higher in men than women $(p=0.035)$, but there was no significant difference in [Hb] between the sexes $(p=0.327)$. Table 2 shows the respiratory function, respiratory pressures, muscle architecture, jump power and handgrip strength of the participants. Men had a higher MT (13.5\%), jump power $(25.3 \%)$ and handgrip strength $(7.0 \%)$ than women $(p \leq 0.001)$, but there were no significant differences in fascicle length, pennation angle, take-off velocity and jump power per $\mathrm{kg}$ of body mass between men and women $(p=0.460, p=0.322, p=0.068, p=0.091$, respectively). Table 2 shows also that $\mathrm{FEV}_{1}(25.3 \%), \mathrm{FEV}_{1}$ pred\% (6.7\%), FVC (14.3\%) PEF (28.5\%), MIP (21.1\%) and MEP $(17.8 \%)$ were higher in men than women $(p \leq 0.040)$. Agegraded performance and weekly hours of training were similar between sexes in the different disciplines $(p=0.274$ and $p=0.281$, respectively) (Table 1 ).

\section{Age-related rate of decline in muscle, respiratory function, blood and performance}

$\mathrm{FEV}_{1}, \mathrm{FVC}, \mathrm{PEF}, \mathrm{MIP}, \mathrm{MEP}, L_{\mathrm{f}}, \mathrm{MT}, V_{\text {off }}$, jump power, jump power per $\mathrm{kg}$ of body mass, handgrip strength, [Hb] and performance correlated negatively with age $(p<0.05)$, while there were no significant correlations between pennation angle, SNIP and Hct with age (Table 3 ). Sex had no significant effect on the age-related rate of decline in any of the parameters $(p=0.985)$. The ANCOVA analysis showed significant differences in the age-related rate
Table 2 Muscle architecture, muscle function, spirometry and respiratory pressure parameters

\begin{tabular}{|c|c|c|c|}
\hline & Men & Women & $P$ value \\
\hline MT (mm) & $28.9 \pm 4.2(56)$ & $25.0 \pm 3.0(15)$ & $0.001 *$ \\
\hline$L_{\mathrm{f}}(\mathrm{mm})$ & $140 \pm 31(55)$ & $137 \pm 19(15)$ & 0.460 \\
\hline Penation angle $\left({ }^{\circ}\right)$ & $11.7 \pm 1.7(55)$ & $11.0 \pm 1.7(15)$ & 0.322 \\
\hline Jump power $(\mathrm{kW})$ & $3.40 \pm 0.86(55)$ & $2.54 \pm 0.59(14)$ & $0.001 *$ \\
\hline Jump power/kg body mass (W/kg) & $41.9 \pm 8.4(55)$ & $38.3 \pm 7.3(14)$ & 0.091 \\
\hline$V_{\text {off }}\left(\mathrm{m} \cdot \mathrm{s}^{-1}\right)$ & $2.35 \pm 0.31(55)$ & $2.17 \pm 0.33(14)$ & 0.068 \\
\hline Hand grip strength (kg) & $47.4 \pm 9.1(45)$ & $34.6 \pm 5.4(15)$ & $<0.001^{*}$ \\
\hline $\mathrm{FEV}_{1}(\mathrm{~L})$ & $4.00 \pm 0.66(45)$ & $2.99 \pm 0.66(14)$ & $0.010 *$ \\
\hline $\mathrm{FEV}_{1 \text { pred } \%}$ & $104 \pm 15(45)$ & $97 \pm 15(14)$ & 0.057 \\
\hline $\mathrm{FVC}(\mathrm{L})$ & $4.9 \pm 0.90(45)$ & $4.2 \pm 1.2(14)$ & $0.040^{*}$ \\
\hline $\mathrm{FVC}_{\text {pred } \%}$ & $106 \pm 15(45)$ & $104 \pm 12(14)$ & 0.398 \\
\hline $\mathrm{FEV}_{1} / \mathrm{FVC}$ & $73.0 \pm 7.7(45)$ & $72.4 \pm 12.7(14)$ & 0.850 \\
\hline $\mathrm{PEF}$ (L/min) & $530 \pm 136(45)$ & $379 \pm 115(14)$ & $<0.001^{*}$ \\
\hline $\mathrm{PEF}_{\text {pred } \%}$ & $104 \pm 24(45)$ & $97 \pm 9.5(14)$ & 0.406 \\
\hline $\mathrm{MIP}\left(\mathrm{cmH}_{2} \mathrm{O}\right)$ & $110 \pm 28(48)$ & $87 \pm 28(14)$ & $0.004 *$ \\
\hline $\mathrm{MEP}\left(\mathrm{cm} \mathrm{H}_{2} \mathrm{O}\right)$ & $158 \pm 36(48)$ & $130 \pm 20(14)$ & $0.009^{*}$ \\
\hline $\mathrm{SNIP}\left(\mathrm{cmH}_{2} \mathrm{O}\right)$ & $103 \pm 38$ & $108 \pm 22(14)$ & 0.588 \\
\hline
\end{tabular}

All data are presented as mean $\pm \mathrm{SD}(N)$

Spirometry predicted values were calculated from the equations of the software provided by the spirometer $M T$ Muscle thickness; $L_{f}$ Fascicle length; $V_{\text {off }}$ Take-off velocity; $F E V_{l}$ Forced expiratory volume in one second; FVC Forced vital capacity; $P E F$ Peak expiratory flow; MIP Maximal inspiratory pressure; $M E P$ Maximal expiratory pressure; $S N I P$ Sniff nasal inspiratory pressure; $L$ Litre; $\mathrm{cmH}_{2} \mathrm{O}$ centimetre of water ${ }^{*} p$ value $<0.05$ denotes significant sex effect 
Table 3 Age-related rate of decline

\begin{tabular}{|c|c|c|c|c|}
\hline & $N$ & $\begin{array}{l}\text { Age-related } \\
\text { rate of } \\
\text { decline }\end{array}$ & $R$ value & $p$ value \\
\hline$L_{\mathrm{f}}$ & 70 & $6.5 \%$ & -0.455 & $<0.001 *$ \\
\hline MT & 71 & $5.1 \%$ & -0.507 & $<0.001 *$ \\
\hline Pennation angle & 70 & $1.8 \%$ & -0.169 & 0.169 \\
\hline$V_{\text {off }}$ & 66 & $6.9 \%$ & -0.744 & $<0.001^{*}$ \\
\hline Jump power & 69 & $10.2 \%$ & -0.626 & $<0.001^{*}$ \\
\hline Jump power/kg body mass & 69 & $8.9 \%$ & -0.677 & $<0.001^{*}$ \\
\hline Handgrip strength & 60 & $7.3 \%$ & -0.565 & $<0.001^{*}$ \\
\hline $\mathrm{FEV}_{1}$ & 59 & $7.1 \%$ & -0.608 & $<0.001^{*}$ \\
\hline FVC & 59 & $6.0 \%$ & -0.450 & $<0.001 *$ \\
\hline $\mathrm{FEV}_{1} / \mathrm{FVC}$ & 59 & $1.2 \%$ & -0.232 & 0.077 \\
\hline PEF & 59 & $4.6 \%$ & -0.295 & $0.023 *$ \\
\hline MEP & 62 & $4.1 \%$ & -0.354 & $0.005 *$ \\
\hline MIP & 62 & $4.8 \%$ & -0.260 & $0.043 *$ \\
\hline SNIP & 62 & $5.4 \%$ & -0.176 & 0.176 \\
\hline $\mathrm{Hb}$ & 66 & $2.6 \%$ & -0.320 & $0.009 *$ \\
\hline Het & 64 & $1.1 \%$ & -0.179 & 0.161 \\
\hline Performance & 58 & $5.9 \%$ & -0.451 & $<0.001 *$ \\
\hline
\end{tabular}

All data are presented as mean $\pm \mathrm{SD}(N)$

$L_{f}$ fascicle length; $M T$ muscle thickness; $F E V_{l}$ forced expiratory volume in one second; $F V C$ forced vital capacity; $P E F$ peak expiratory flow; $M I P$ maximal inspiratory pressure; $M E P$ maximal expiratory pressure; SNIP sniff nasal inspiratory pressure; $H b$ haemoglobin; $H c t$ haematocrit

${ }^{*} p$ value $<0.05$ denotes significant decline with age

of decline of the different parameters $(p=0.032)$, with the $[\mathrm{Hb}]$ showing the lowest age-related rate of decline (Table 3). An additional ANCOVA analysis excluding $[\mathrm{Hb}]$ showed no significant difference in the age-related rate of decline between parameters $(p=0.102)$.

\section{Determinants of track cycling performance}

The major determinant of 200, 500 and $2000 \mathrm{~m}$ performance was $V_{\text {off }}\left(R_{\text {adj }}^{2}=0.690,0.794\right.$ and 0.769 , respectively; $p<0.001)$. There was an additional contribution of PEF in $200 \mathrm{~m}$ performance $\left(R_{\text {adj }}^{2}=0.765 ; p=0.019\right)$. $R^{2}$ adj increased to 0.844 in $500 \mathrm{~m}$ performance after adding pennation angle to the model $(p<0.001)$ and 0.906 after adding MT $(p<0.001) . R^{2}$ adj increased to 0.823 in $2000 \mathrm{~m}$ performance after adding to the model pennation angle $(p<0.001)$ and 0.855 after adding age $\left(R_{\text {adj }}^{2}=0.855, p<0.001\right)$. The major determinant of $V_{\text {off }}$ was MT $\left(R_{\text {adj }}^{2}=0.409 ; p<0.001\right) . R_{\text {adj }}^{2}$ increased to 0.591 after adding age to the model $(p<0.001)$ and 0.654 after adding sex $(p<0.001)$.

\section{Discussion}

The main observation of the present study is that respiratory function, muscle architecture, muscle function and cycling performance showed proportional rates of annual decline that was similar in men and women. This suggests that ageing is uniform between physiological systems. In addition, we observed that the take-off velocity during a countermovement jump was the main determinant of cycling performance, irrespective of sex and age.

\section{Interrelation between the age-related rate of decline of peripheral muscle, respiratory function and respiratory muscles}

It has been reported that the age-related rate of decline in muscle function, respiratory function and respiratory muscle strength does not differ significantly between athletes and non-athletes (Degens et al. 2013; Pearson et al. 2002). Here, we extend these observations and show that respiratory function, respiratory muscle strength, MT, $L_{\mathrm{f}}$ and jump power in cycling athletes decline at similar rates with age. These changes were accompanied with a proportional decline in cycling performance (Table 3, Fig. 1). This suggests that ageing proportionately affects different physiological systems, regardless of the physical activity levels or the type of training practiced (Bagley et al. 2019; Degens et al. 2013; Michaelis et al. 2008; Pearson et al. 2002). Indeed, ageing affects the performance in different athletic disciplines similarly (Ganse et al. 2018) and is seen in athletics, swimmers and even chess players (Berthelot et al. 2011) and suggests that ageing affects all human systems similarly. The uniformity in the decline of different physiological parameters and performance suggests that there is a common cause of the detrimental changes in all sorts of organ system during ageing, which may well be a stochastic accumulation of (micro) damage over time (Degens 2012).

\section{Respiratory function and respiratory muscle strength}

Similar to previous observations in non-athletes, endurance and power athletes (Degens et al. 2013), we observed here a significant age-related rate of decline in $\mathrm{FEV}_{1}, \mathrm{FVC}$, PEF, MIP and MEP, irrespective of sex. Even though pulmonary function may be better in master athletes than agematched non-athletes (Degens et al. 2013; Hagberg et al. 1988), which may be explicable by selection where men and women with better pulmonary function remain active, they still suffer from an age-related reduction in pulmonary function. Indeed, in this cohort of track cyclists, 
Fig. 1 a Age-related rate of decline in muscle architecture, jump power per $\mathrm{kg}$ of body mass, handgrip strength and haemoglobin concentration $[\mathrm{Hb}]$ as a proportion of the value at the age of 35 years. Closed circles represent men and open circles women. ${ }^{*} p$-value $<0.05$ denotes significant difference in the age-related decline. $\mathbf{b}$ Age-related rate of decline in respiratory function, respiratory pressure, and performance as a proportion of the value at age 35 years. Closed circles represent men and open circles women
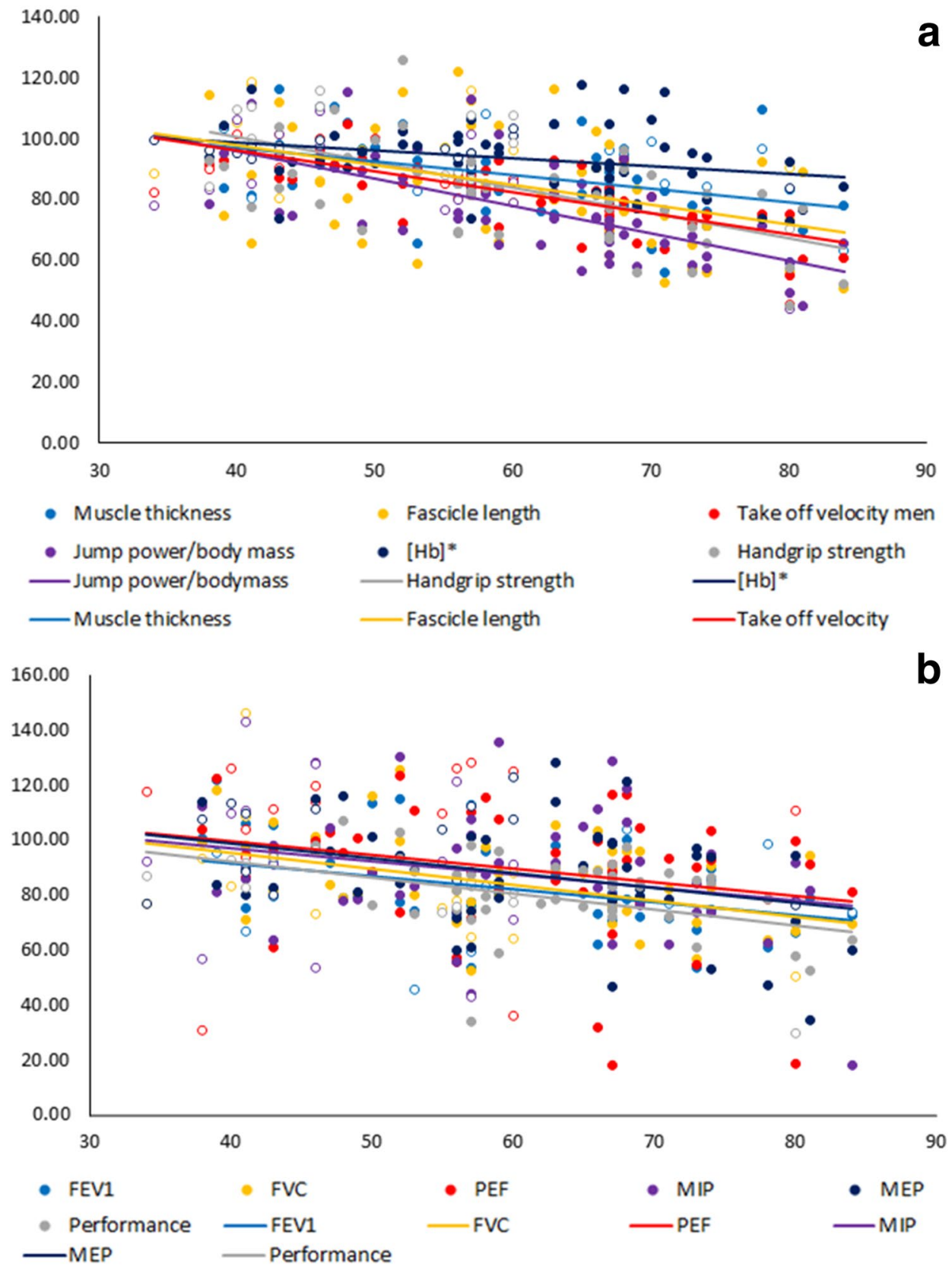

predictive values of respiratory function are around $100 \%$, supporting the notion that physical activity does not protect against the age-related decline in pulmonary function (Roman et al. 2016; Saltin and Grimby 1968). Part of the decline in spirometry may be attributable to the loss of respiratory muscle strength (Degens et al. 2013), but also other factors, such as decrements in lung recoil and chest compliance (Lesauskaite and Ebejer 1999), will contribute to an age-related reduction in ventilator capacity.

\section{Muscle architecture and muscle function}

Similar to previous observations in non-athletes (Narici et al. 2003), we found that MT declined by $0.51 \%$ per year, which was accompanied by an annual $0.65 \%$ decline in $L_{\mathrm{f}}$. This indicates that even in master cyclists, ageing leads into a reduction of the number of sarcomeres in series. As resistance training-induced hypertrophy is accompanied by an increase (Erskine et al. 2011; Reeves et al. 2004) and the 
disuse-induced atrophy by a decrease (Narici et al. 2002) in pennation angle. It is perhaps somewhat surprising that we did not find an age-related decrease in pennation angle. It should be noted, however, that MT - the product of $L_{\mathrm{f}}$ and the sine of the pennation angle-is fully explicable by a decrease in $L_{\mathrm{f}}$. The implication of these changes is that the force-generating capacity is not affected, but the shortening velocity of the muscle, and hence, the ability to generate power-product of force and velocity-is reduced (Degens et al. 2009). This impaired power-generating capacity during ageing may be further aggravated by the selective atrophy of type II fibres (Barnouin et al. 2017) and slowing of type I fibres, even in athletes (Korhonen et al. 2006). Such a reduced shortening velocity may have functional consequences, as in non-athletes the age-related reduction in $V_{\text {off }}$ during a CMJ explained 30-40\% of the variation of walking speed (Maden-Wilkinson et al. 2015). Therefore, with age, muscle quality apart from muscle mass, may be an important contributor to the decline of muscle function with age (Goodpaster et al. 2006).

\section{Determinants of track cycling performance}

Here, we found that $V_{\text {off }}$ was the main determinant of cycling performance in $\leq 2000 \mathrm{~m}$ events, irrespective of age and sex. While this may indicate a slowing of the muscle contractile properties, it may be explicable by a diminished force generation ability, which would cause the muscles to work on a slower part of the force-velocity relationship (Degens 2019). Unfortunately, we did not directly measure the forcegenerating capacity of the muscle, but in support of this, we found that MT, an indirect measure of force-generating capacity (Muraki et al. 2013), was the major determinant of $V_{\text {off }}$ and correlated with the power-generating ability of the master cyclists (Fig. 2). Future studies should address whether indeed there is an age-related slowing in muscle contractile properties and/or, a diminished force-generating capacity that caused this age-related decline in $V_{\text {off }}$ during a countermovement jump and concomitant decline in cycling performance.

\section{Limitations}

Although the women were on average younger than the men, when split by age and sex into 15 -year groups, physiological parameters remained significantly different $(p<0.05)$ between sexes. The relatively low number of women in the study may cause weaker correlations in the women than the men, but even so, the data of the women overlap those of the men in Fig. 1. This indicates that even though the number of women was low, the pattern emerges that men and women show a similar age-related decline. No control group was included in this study, perhaps making it difficult to assess whether track cycling attenuates the age-related decline in the function of different physiological functions. However,
Fig. 2 a Relationship between Voff (take-off velocity) and power per $\mathrm{kg}$ of body mass: $R^{2}=0.7822, p<0.001 . \mathbf{b}$ Between muscle thickness and power per $\mathrm{kg}$ of body mass: $R^{2}=0.2275, p<0.001$. c Between muscle thickness and Voff: $R^{2}=0.3577, p<0.001$
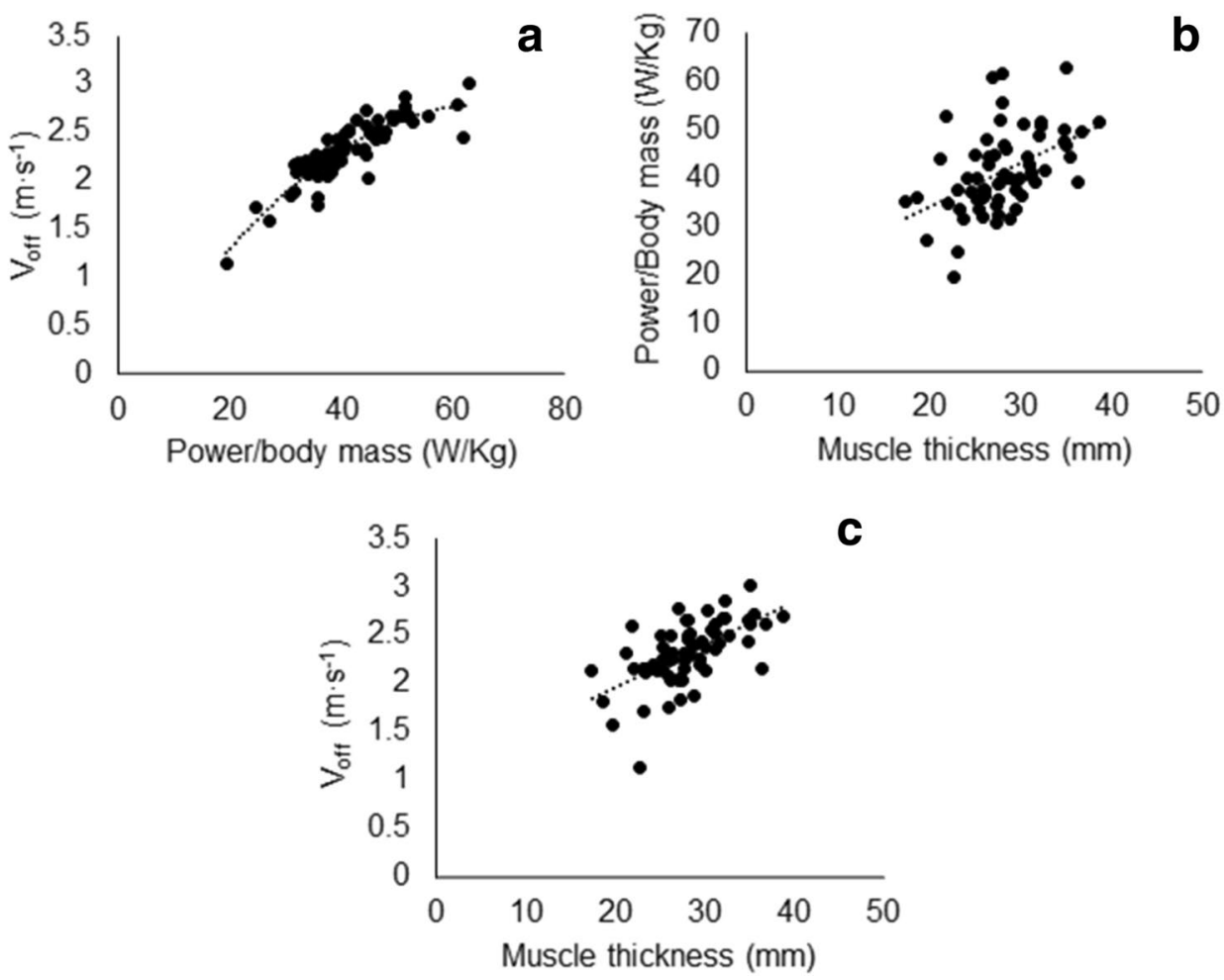
the \%predicted values of the spirometry parameters may indicate that regular track cycling does not attenuate the age-related decline in pulmonary function (Table 2). However, the cross-sectional nature of the study somewhat limits this assumption and further longitudinal study is necessary to confirm this finding. Other studies have shown that the $\%$ decline in jump power (Michaelis et al. 2008) and $\mathrm{VO}_{2 \max }$ (Tanaka and Seals 2008) is similar in athletes and non-athletes, suggesting that regular exercise does not attenuate the ageing process per se (Degens 2012).

\section{Conclusion}

It was found that the uniform decline in peripheral muscle architecture and function, respiratory function and respiratory muscle strength with age, in master cyclists, was accompanied by a proportional rate of decline in performance. It appeared that $V_{\text {off }}$ was the major determinant of performance (at least in $\leq 2000 \mathrm{~m}$ events), irrespective of age and sex. It remains to be seen whether this decline in take-off velocity during a countermovement jump $\left(V_{\text {off }}\right)$ is attributable to a slowing of the contractile properties and/or a loss of force-generating capacity of the muscle. However, our observation that muscle thickness, a proxy for forcegenerating capacity, correlated with $V_{\text {off }}$ suggests that the decline in force is the main cause of the decline in $V_{\text {off }}$, rather than slower contractile properties.

Acknowledgements We would like to thank Prof Jamie McPhee, for his valuable teaching of the ultrasound technique used in this manuscript and Dr Alex Ireland for his collaboration to set up the project and support in collecting data.

Author contributions PD and MD wrote the manuscript, collected data, and analysed data. KI, AA, BG, FZ, GM, RM, MS, JC, and BG collected data. HD and LB conceived and designed the study, collected data, and actively contributed in the writing process of the manuscript and data analysis. All authors read and approved the manuscript.

Funding This study is part of a project funded by DTA3/COFUND Marie Skłodowska-Curie $\mathrm{PhD}$ programme.

Availability of data and material The datasets generated and/or analysed during the current study are available from the corresponding author on reasonable request.

Code availability Not applicable.

\section{Declarations}

Conflict of interest We declare that any of the authors listed in the authors list do not have a conflict of interest to declare.

Ethics approval The study was approved by the Science and Engineering Research Ethics Committee at Manchester Metropolitan University.
Consent to participate All participants provided written informed consent to participate in the study, conforming to the Declaration of Helsinki.

Consent to publish The authors declare that all participants provided consent to publish the data reported in this study.

Open Access This article is licensed under a Creative Commons Attribution 4.0 International License, which permits use, sharing, adaptation, distribution and reproduction in any medium or format, as long as you give appropriate credit to the original author(s) and the source, provide a link to the Creative Commons licence, and indicate if changes were made. The images or other third party material in this article are included in the article's Creative Commons licence, unless indicated otherwise in a credit line to the material. If material is not included in the article's Creative Commons licence and your intended use is not permitted by statutory regulation or exceeds the permitted use, you will need to obtain permission directly from the copyright holder. To view a copy of this licence, visit http://creativecommons.org/licenses/by/4.0/.

\section{References}

Bagley L, McPhee JS, Ganse B, Müller K, Korhonen MT, Rittweger J, Degens H (2019) Similar relative decline in aerobic and anaerobic power with age in endurance and power master athletes of both sexes. Scand J Med Sci Sports 29(6):791-799. https://doi.org/10. 1111/sms.13404

Barnouin Y, McPhee JS, Butler-Browne G, Bosutti A, De Vito G, Jones DA, Narici M, Behin A, Hogrel JY, Degens H (2017) Coupling between skeletal muscle fiber size and capillarization is maintained during healthy aging. J Cachexia Sarcopenia Muscle 8(4):647-659. https://doi.org/10.1002/jcsm.12194

Berthelot G, Len S, Hellard P, Tafflet M, Guillaume M, Vollmer J-C, Gager B, Quinquis L, Marc A, Toussaint J-F (2011) Exponential growth combined with exponential decline explains lifetime performance evolution in individual and human species. Age (Dordr) 34(4):1001-1009. https://doi.org/10.1007/s11357-011-9274-9

Bhatt M, Wankhede T, Thapa B, Malhotra VK, Hira D, Kushwaha AS (2015) Relationship between short-distance run and variables of pulmonary function tests. Natl J Physiol Pharm Pharmacol 5(2):149-152. https://doi.org/10.5455/njppp.2015.5.051220141

Brennan SF, Cresswell AG, Farris DJ, Lichtwark GA (2017) In vivo fascicle length measurements via B-mode ultrasound imaging with single vs dual transducer arrangements. J Biomech 64:240244. https://doi.org/10.1016/j.jbiomech.2017.09.019

Couppé C, Svensson RB, Grosset J-F, Kovanen V, Nielsen RH, Olsen MR, Larsen JO, Praet SFE, Skovgaard D, Hansen M, Aagaard P, Kjaer M, Magnusson SP (2014) Life-long endurance running is associated with reduced glycation and mechanical stress in connective tissue. Age (Dordr) 36(4):1-19. https://doi.org/10.1007/ s11357-014-9665-9

Degens H (2012) Determinants of skeletal muscle hypertrophy and the attenuated hypertrophic response at old age. J Sports Med Doping Stud

Degens H (2019) Chapter 19: human ageing: impact on muscle force and power. In: Zoladz JA (ed) Muscle and exercise physiology. Academic Press, London, pp 423-432

Degens H, Alway SE (2006) Control of muscle size during disuse, disease, and aging. Int J Sports Med 27(2):94-99

Degens H, Erskine RM, Morse CI (2009) Disproportionate changes in skeletal muscle strength and size with resistance training and ageing. J Musculoskelet Neuronal Interact 9(3):123-129 
Degens H, Maden-Wilkinson TM, Ireland A, Korhonen MT, Suominen H, Heinonen A, Radak Z, McPhee JS, Rittweger J (2013) Relationship between ventilatory function and age in master athletes and a sedentary reference population. Age 35(3):1007-1015

Degens H, Stasiulis A, Skurvydas A, Statkeviciene B, Venckunas T (2019) Physiological comparison between non-athletes, endurance, power and team athletes. Eur J Appl Physiol 119(6):13771386. https://doi.org/10.1007/s00421-019-04128-3

Dempsey JA, McKenzie DC, Haverkamp HC, Eldridge MW (2008) Update in the understanding of respiratory limitations to exercise performance in fit, active adults. Chest 134(3):613-622

Efstathiou ID, Mavrou IP, Grigoriadis KE (2016) Correlation between maximum inspiratory pressure and hand-grip force in healthy young and middle-age individuals. Respir Care 61(7):925-929. https://doi.org/10.4187/respcare.04319

Erskine RM, Jones DA, Maffulli N, Williams AG, Stewart CE, Degens $\mathrm{H}$ (2011) What causes in vivo muscle specific tension to increase following resistance training? Exp Physiol 96(2):145-155. https:// doi.org/10.1113/expphysiol.2010.053975

Ganse B, Ganse U, Dahl J, Degens H (2018) Linear decrease in athletic performance during the human life span. Front Physiol 9:1100. https://doi.org/10.3389/fphys.2018.01100

George JM, Sen K, Raveendran C (2014) Evaluation of the effect of exercise on pulmonary function in young healthy adults. Int $\mathbf{J}$ Biomed Adv Res 5(6):308-312

Goodpaster BH, Park SW, Harris TB, Kritchevsky SB, Nevitt M, Schwartz AV, Simonsick EM, Tylavsky FA, Visser M, Newman AB, Hlth ABCS, for the Health ABCS (2006) The loss of skeletal muscle strength, mass, and quality in older adults: the health, aging and body composition study. J Gerontol A Biol Sci Med Sci 61(10):1059-1064. https://doi.org/10.1093/gerona/61.10.1059

Hagberg JM, Yerg JE, Seals DR (1988) Pulmonary fucntion in young and older athletes and untrained men. J Appl Physiol 65(1):101-105

Hankinson JL, Odencrantz JR, Fedan KB (1999) Spirometric reference values from a sample of the general US population. Am J Respir Crit Care Med 159(1):179-187. https://doi.org/10.1164/ajrccm. 159.1.9712108

Harik-Khan RI, Wise RA, Fozard JL (1998) Determinants of maximal inspiratory pressure. The Baltimore longitudinal study of aging. Am J Respir Crit Care Med 158(5 Pt 1):1459-1464. https://doi. org/10.1164/ajrccm.158.5.9712006

Hautmann H, Hefele S, Schotten K, Huber R (2000) Maximal inspiratory mouth pressures (PIMAX) in healthy subjects-what is the lower limit of normal? Respir Med 94(7):689-693

Korhonen MT, Cristea A, Alén M, Häkkinen K, Sipilä S, Mero A, Viitasalo JT, Larsson L, Suominen H (2006) Aging, muscle fiber type, and contractile function in sprint-trained athletes. J Appl Physiol 101(3):906-917. https://doi.org/10.1152/japplphysiol. 00299.2006

Lesauskaite V, Ebejer MJ (1999) Age-related changes in the respiratory system. Maltese Med J 11(1):2

Leyk D, Ruther T, Wunderlich M, Sievert A, Essfeld D, Witzki A, Erley O, Kuchmeister G, Piekarski C, Lollgen H (2010) Physical performance in middle age and old age good news for our sedentary and aging society. Deutsch Arzteblatt Int 107(46):809-816. https://doi.org/10.3238/arztebl.2010.0809

Maden-Wilkinson TM, McPhee JS, Jones DA, Degens H (2015) Agerelated loss of muscle mass, strength, and power and their association with mobility in recreationally-active older adults in the United Kingdom. J Aging Phys Act 23(3):352-360. https://doi. org/10.1123/japa.2013-0219

Martin JC, Farrar RP, Wagner BM, Spirduso WW (2000) Maximal power across the lifespan. J Gerontol A Biol Sci Med Sci 55(6):M311-M316. https://doi.org/10.1093/gerona/55.6.M311
Martin JC, Davidson CJ, Pardyjak ER (2007) Understanding sprintcycling performance: the integration of muscle power, resistance, and modeling. Int J Sports Physiol Perform 2(1):5-21. https://doi. org/10.1123/ijspp.2.1.5

McClaran SR, Babcock MA, Pegelow DF, Reddan WG (1985) Dempsey JA (1995) Longitudinal effects of aging on lung function at rest and exercise in healthy active fit elderly adults. J Appl Physiol 78(5):1957-1968. https://doi.org/10.1152/jappl.1995.78.5.1957

McKendry J, Breen L, Shad BJ, Greig CA (2018) Muscle morphology and performance in master athletes: a systematic review and metaanalyses. Ageing Res Rev 45:62-82. https://doi.org/10.1016/j.arr. 2018.04.007

McPhee JS, French DP, Jackson D, Nazroo J, Pendleton N, Degens $\mathrm{H}$ (2016) Physical activity in older age: perspectives for healthy ageing and frailty. Biogerontology (Dordr) 17(3):567-580. https:// doi.org/10.1007/s10522-016-9641-0

McPhee JS, Cameron J, Maden-Wilkinson T, Piasecki M, Yap MH, Jones DA, Degens H (2018) The contributions of fiber atrophy, fiber loss, in situ specific force, and voluntary activation to weakness in sarcopenia. J Gerontol 73(10):1287-1294. https://doi.org/ 10.1093/gerona/gly040

Michaelis I, Kwiet A, Gast U, Boshof A, Antvorskov T, Jung T, Rittweger J, Felsenberg D (2008) Decline of specific peak jumping power with age in master runners. J Musculoskel Neuron Interact $8(1): 64-70$

Miller MR, Hankinson J, Brusasco V, Burgos F, Casaburi R, Coates A, Crapo R, Pv E, Van Der Grinten C, Gustafsson P (2005) Standardisation of spirometry. Eur Respir J 26(2):319-338

Muraki S, Fukumoto K, Fukuda O (2013) Prediction of the muscle strength by the muscle thickness and hardness using ultrasound muscle hardness meter. Springerplus 2(1):1-7. https://doi.org/10. 1186/2193-1801-2-457

Narici MV, Maganaris CN, Reeves ND (2002) Muscle and tendon adaptations to ageing and spaceflight. J Gravit Physiol 9(1):P137-P138

Narici MV, Maganaris CN, Reeves ND, Capodaglio P (2003) Effect of aging on human muscle architecture. J Appl Physiol 95(6):2229_ 2234. https://doi.org/10.1152/japplphysiol.00433.2003

Pearson SJ, Young A, Macaluso A, Devito G, Nimmo MA, Cobbold M, Harridge SDR (2002) Muscle function in elite master weightlifters. Med Sci Sports Exerc 34(7):1199-1206. https://doi.org/10. 1097/00005768-200207000-00023

Phillips KE, Hopkins WG (2020) Determinants of cycling performance: a review of the dimensions and features regulating performance in elite cycling competitions. Sports Med Open 6(1). https://doi.org/10.1186/s40798-020-00252-z

Reeves ND, Narici MV, Maganaris CN (2004) In vivo human muscle structure and function: adaptations to resistance training in old age. Exp Physiol 89(6):675-689

Roman MA, Rossiter HB, Casaburi R (2016) Exercise, ageing and the lung. Eur Respir J 48(5):1471-1486

Saltin B, Grimby G (1968) Physiological analysis of middle-aged and old former athletes. Comparison with still active athletes of the same ages. Circulation 38(6):1104-1115. https://doi.org/10.1161/ 01.cir.38.6.1104

Sawaya Y, Ishizaka M, Kubo A, Sadakiyo K, Yakabi A, Sato T, Shiba T, Onoda K, Maruyama H (2018) Correlation between skeletal muscle mass index and parameters of respiratory function and muscle strength in young healthy adults according to gender. $\mathbf{J}$ Phys Ther Sci 30(12):1424-1427. https://doi.org/10.1589/jpts. 30.1424

Stark T, Walker B, Phillips J, Fejer R, Beck R (2011) Hand-held dynamometry correlation with the gold standard isokinetic dynamometry: a systematic review. PM R 3:472-479. https://doi. org/10.1016/j.pmrj.2010.10.025

Tanaka H, Seals DR (2003) Invited review: dynamic exercise performance in masters athletes: insight into the effects of primary 
human aging on physiological functional capacity. J Appl Physiol 95(5):2152-2162. https://doi.org/10.1152/japplphysiol.00320. 2003

Tanaka H, Seals DR (2008) Endurance exercise performance in masters athletes: age-associated changes and underlying physiological mechanisms. J Physiol 586(1):55-63. https://doi.org/10.1113/ jphysiol.2007.141879

The American Thoracic Society (2002) ATS/ERS statement on respiratory muscle testing. Am J Respir Crit Care Med 166(4):518-624. https://doi.org/10.1164/rccm.166.4.518
Union Cycliste Internationale (2021) Masters best performances. Accessed 15/01/2021

Publisher's Note Springer Nature remains neutral with regard to jurisdictional claims in published maps and institutional affiliations.

\section{Authors and Affiliations}

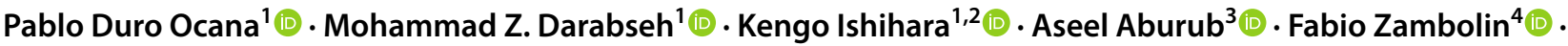

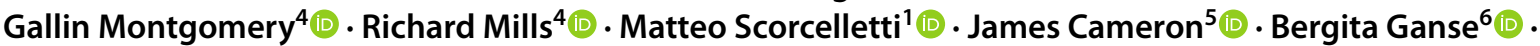 Hans Degens ${ }^{1,7}$ (i) $\cdot$ Liam Bagley ${ }^{1}$ (i)}

1 Department of Life Sciences, Centre of Musculoskeletal Sciences and Sport Medicine, Manchester Metropolitan University, John Dalton Building; Chester Street, Manchester M1 5GD, UK

2 Department of Food Sciences and Human Nutrition, Faculty of Agriculture, Ryukoku University, Shiga 520-2194, Japan

3 School of Allied Health Professions, Keele University, Staffordshire ST5 5BG, UK

4 Department of Sport and Exercise Sciences, Centre of Musculoskeletal Sciences and Sport Medicine, Manchester Metropolitan University, All Saints Building; Oxford Rd, Manchester M15 6BW, UK
5 Department of Health Professions, Manchester Metropolitan University, Cavendish Building; Cavendish Street, Manchester M1 6BG, UK

6 Department of Surgery, Innovative Implant Development, Saarland University, Kirrberger Str. 1, 66421 Homburg, Germany

7 Institute of Sport Science and Innovations, Lithuanian Sports University, Kaunas, Lithuania 